$\stackrel{N / N}{=}$

Global burnals Inc.

है 20 and

\title{
Intercultural Adaptation and Mental Health of Indonesian Health Workers Coming to Japan under the Economic Partnership Agreement
}

By Fumiko Sato

Aino University

Abstract- Following the Economic Partnership Agreement (EPA) between Japan and Indonesia coming into effect, acceptance of Indonesian nursing and care worker candidates began in 2008. From the following fiscal year, acceptance was expanded to include the Philippines and Vietnam. The medical and nursing care fields in Japan are gradually becoming internationalized. We speculated that EPA candidates would adapt to living and working in Japan, which has a different culture from their own country. This study assessed their adaptability to Japanese culture, mental health, and the clarified factors related to their mental health, based on the results of a quantitative survey.

Keywords: EPA, indonesian, intercultural adaptation, mental health.

GJMR-K Classification: NLMC Code: WA 305

Strictly as per the compliance and regulations of:

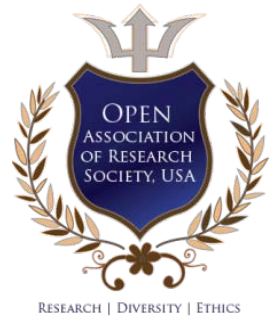

(C) 2019. Fumiko Sato. This is a research/review paper, distributed under the terms of the Creative Commons AttributionNoncommercial 3.0 Unported License http://creativecommons.org/licenses/by-nc/3.0/), permitting all non-commercial use, distribution, and reproduction in any medium, provided the original work is properly cited. 


\title{
Intercultural Adaptation and Mental Health of Indonesian Health Workers Coming to Japan under the Economic Partnership Agreement
}

\author{
Fumiko Sato
}

\begin{abstract}
Following the Economic Partnership Agreement (EPA) between Japan and Indonesia coming into effect, acceptance of Indonesian nursing and care worker candidates began in 2008. From the following fiscal year, acceptance was expanded to include the Philippines and Vietnam. The medical and nursing care fields in Japan are gradually becoming internationalized. We speculated that EPA candidates would adapt to living and working in Japan, which has a different culture from their own country. This study assessed their adaptability to Japanese culture, mental health, and the clarified factors related to their mental health, based on the results of a quantitative survey.
\end{abstract}

Keywords: EPA, indonesian, intercultural adaptation, mental health.

\section{INTRODUCTION}

apan has started receiving nurse and care worker candidates from Indonesia based on the Economic Partnership Agreement (EPA), which came into effect in 2008. Furthermore, from the following year, nursing and care candidates have come to Japan from the Philippines and Vietnam (Ministry of Health, Labor and Welfare 2018). Foreign nurses and care worker candidates are aiming to obtain national qualifications while receiving employment and training at each facility. Many of the candidates have experience as nurses in their home countries and have nursing knowledge and skills; however, they cannot work as regular nurses or care workers in Japan unless they pass the national examination (Hatanaka and Tanaka 2012).

After obtaining the national qualification, they are allowed to continue working without a limitation to their length of stay; however, about $20 \%$ of those who have acquired national qualifications returned home (Ikeda 2014). There were many reasons for returning home, such as to care for parents and get married; however, there were also cases where the respondents were frustrated by not being able to use the Japanese well and placed in harsh working environment with strict rules and long working hours (Ikeda 2014).

As the nurses adapt to the different culture in Japan while working, they can feel stressed, which Japanese people may not even notice. The accumulation of stress influences on mental health.

Author: Aino University, Faculty of Health Science, Department of Nursing.e-mail: f-sato@ns-u.aino.ac.jp
Ishikawa and Takahashi (1993) noted that cultural differences, including changes in lifestyle, language, climate, and other environmental changes caused by overseas migration could be very confusing to the migrant. In many cases, the accumulation of daily stresses leads to mental and physical fatigue, which, if left untreated, can cause physical and mental problems. Indeed, psychiatric issues are increasing among foreign people living in Japan who have to deal with various stresses in their daily lives (Onishi 2003).

In previous studies, it reported that the mental health of foreign people living in Japan might be affected by living and adapting to a different culture. There are few studies focusing on the intercultural adaptation and mental health of foreign healthcare workers ${ }^{1)}$ under the EPA. Therefore, this study aimed to clarify intercultural adaptation, mental health, and factors related to their mental health among Indonesian healthcare workers who came to Japan under the EPA.

\section{Methods}

\section{a) Participants and data collection}

Participants were Indonesian healthcare workers who came to Japan under the EPA. Generally, recipient facilities do not announce their acceptance of Indonesian EPA migrant workers to the public. Therefore, the participants were those employed at medical and care giving facilities that openly accepted these workers. The identity of these facilities was only accessible to the author. Data collection was performed between November 2012 and March 2013; survey request forms and questionnaires mailed to the managers of these recipient facilities (206 workers from 87 facilities). The managers distributed the survey to Indonesian EPA workers working at the respective facilities. Only those workers who consented to cooperate for the survey completed the questionnaire and returned anonymously.

\section{b) Study instrument}

\section{i. Demographics}

We obtained the demographics of the study group from questions addressing population and household conditions as well as socioeconomic conditions. In the population and household conditions, gender, age, marital status, religion, number of years 
living in Japan, level of Japanese language proficiency. In the socioeconomic conditions, we examined academic background, classification of the current workplace, number of years of working at the current workplace, work pattern, target national qualification, status of acquiring the national qualification.

\section{ii. Intercultural adaptation}

The adaptation scale for international students in Japan developed by Uehara (Uehara 1992), concerning The Freshman's Scale of Adjustment by Baker (Baker et al. 1985) (Baker and Siryk 1986) was adopted for measuring the level of intercultural adaptation. The scale is composed of 56 questions in five areas: "Learning/Research," "Mental and Physical Health/Emotion," "Interpersonal Relationships," "Culture", and "Living Comfort/Economy." For each scale, respondents were asked to choose from five responses (1. Not applicable at all $<1>$ to 5 . Very much applicable $<5>$ ). This scale is frequently used as an adaptation scale in Japan, and its validity of reliability was confirmed (Sasaki and Mizuno 2000). In this study, some questions were modified so they applied to Indonesian health workers and simplified to a total of 34 items.

\section{iii. Level of mental health (GHQ28)}

We used the General Health Questionnaire $(\mathrm{GHQ})$ as a measure for the mental health level of the participants. GHQ is a scale for measuring mental health developed by Goldberg (Goldberg and Hillier 1979) and used in various fields (Nakayama and Daibo 1985). GHQ has three versions: GHQ60 (60-item version) as well as its shortened versions GHQ30 (30-item version) and GHQ28 (28-item version). Fukunishi (1990) has reported the effectiveness of these shortened versions. In this study, GHQ28 was used, taking into consideration the burden of extensive questioning of the participants. The grading method was as follows: following the guidelines for the Japanese version (Nakawaga and Daibow 1985), we graded the four choices for each item as 0-0-1-1 points, and the total score was determined. The highest score of the GHQ28 is 28. The higher score indicates a lower level of mental health. According to the guidelines, individuals scoring 5 or less are considered to be healthy, whereas those scoring 6 points or higher are at risk of mental problems. Many studies have examined the reliability and validity of GHQ28 in various populations and reported its usefulness independent of cultural differences, language, and religion (Nakagawa and Daibow 1985).

\section{c) Data analysis}

Descriptive statistics were applied to assess the demographics, intercultural adaptation, and mental health status of the participants. The total score of GHQ28 was used to divide the respondents into two groups: a "risk absent group" and a "risk present group," based on the GHQ28 total score. For categorical variables, we used the Chi-Square test or Fisher's exact test, and for quantitative variables, an unpaired t-test was performed to investigate the determinant factors for mental health. We used SPSS Ver. Twenty for Windows for the analyses, with the level of significance at $0.05 \%$ for both sides.

\section{d) Ethical considerations}

This study was approved by the Ethics Review Board of Senri Kinran University, School of Nursing, Japan. The purpose of the study was clearly stated on the title page of each questionnaire. In addition, it also mentioned that cooperation for the anonymous survey was voluntary.

\section{Results}

The questionnaire was distributed to 87 facilities nationwide. Six of the 87 facilities returned 15 uncompleted questionnaires for various reasons such as the Indonesian workers had already returned to their home country or had resigned the facility. We obtained responses from 71 of 191 questionnaires sent to migrant workers in 35 facilities (a facility recovery rate of $43.2 \%$, and the actual participation rate of $37.2 \%$ ).

\section{a) Demographics}

Table 1 showed the results.

Of the 71 participants, 57 (80.3\%) were female, the mean age was 28.8 years, and $70.0 \%$ of participants were single. For the years of living abroad, $50.7 \%$ had lived in Japan for at least three years. As for Japanese language proficiency, $56.3 \%$ of respondents answered that they still had difficulty in daily conversation. About the highest level of education, $81.7 \%$ graduated from the vocational school, which provides three years of professional education after graduating from high school. In terms of the classification of current workplaces, hospitals (71.4\%) were the most common, followed by aged-care nursing homes (20.0\%), and long-term health care facilities (8.6\%). The national qualification aimed for by the majority of participants was the nursing qualification (73.1\%), followed by the care worker qualification (26.9\%). The status of acquisition of the national qualification was "not acquired" in $61.4 \%$ of participants, and "acquired" in $38.6 \%$ 
Table 1: Demographics of the subjects $(\mathrm{N}=71)$

\begin{tabular}{|c|c|}
\hline Items & \\
\hline \multicolumn{2}{|l|}{$<$ Population and household conditions $>$} \\
\hline \multicolumn{2}{|l|}{ Gender } \\
\hline Female & $57(80.3)$ \\
\hline Male & $14(19.7)$ \\
\hline Age (range : 24-36) & $28.8( \pm 2.7)$ \\
\hline \multicolumn{2}{|l|}{ Marital Status } \\
\hline Single & $49(70.0)$ \\
\hline Married & $21(30.0)$ \\
\hline \multicolumn{2}{|l|}{ Religion } \\
\hline Islam & $43(60.0)$ \\
\hline Other & $28(39.4)$ \\
\hline \multicolumn{2}{|l|}{ Number of year living in Japan } \\
\hline Less than 3 year & $35(49.2)$ \\
\hline 3 years or more & $36(50.7)$ \\
\hline \multicolumn{2}{|l|}{ Level of Japanese language proficiency } \\
\hline Still find daily conversation difficult & $40(56.3)$ \\
\hline No problems in daily conversation and & $31(43.7)$ \\
\hline \multicolumn{2}{|l|}{$<$ Socioeconomic conditions $>$} \\
\hline \multicolumn{2}{|l|}{ Academic background } \\
\hline Vocational school & $58(81.7)$ \\
\hline University or above & 13(18.3) \\
\hline \multicolumn{2}{|l|}{ Classification of the current workplace } \\
\hline Hospital & $50(71.4)$ \\
\hline Aged-care nursing home & 14(20.0) \\
\hline Long-term health care facility & $6(8.6)$ \\
\hline Number of years working at thecurrent workplace & $2.2( \pm 1.2)$ \\
\hline \multicolumn{2}{|l|}{ Work pattern } \\
\hline Part time & $6(8.7)$ \\
\hline Full time & 63(91.3) \\
\hline \multicolumn{2}{|l|}{ Target national qualification } \\
\hline Nurse & $49(73.1)$ \\
\hline Care worker & $18(26.9)$ \\
\hline \multicolumn{2}{|l|}{ Status of acquiring the national qualification } \\
\hline Not acquired & $43(61.4)$ \\
\hline Acquired & 27(38.6) \\
\hline
\end{tabular}

Values are $\mathrm{N}(\%)$ or mean $\pm \mathrm{SD}$ (Standard Deviation). The totals for some categories do not equal due to missing data. 


\section{b) Intercultural adaptation}

The average score was $90.1( \pm 14.9)$. The lowest score was 59 , and the highest score was 127 . On this scale, the higher the score, the lower the adaptability to the different cultures. Thirty-three out of 71 subjects (46.4\%) showed higher scores than the average score. Fig. 1 shows the distribution of total scores on this scale. The Cronbach alpha (reliability coefficient) in this study was 0.85 . The scores for each item were calculated by summing the items in the subscales of the five areas. Table 2 shows the average value and standard deviation of all items, and each area. Also, we calculated the percentage of each area to the perfect score as the \% score. The "culture" area was the highest at $56.3 \%$.

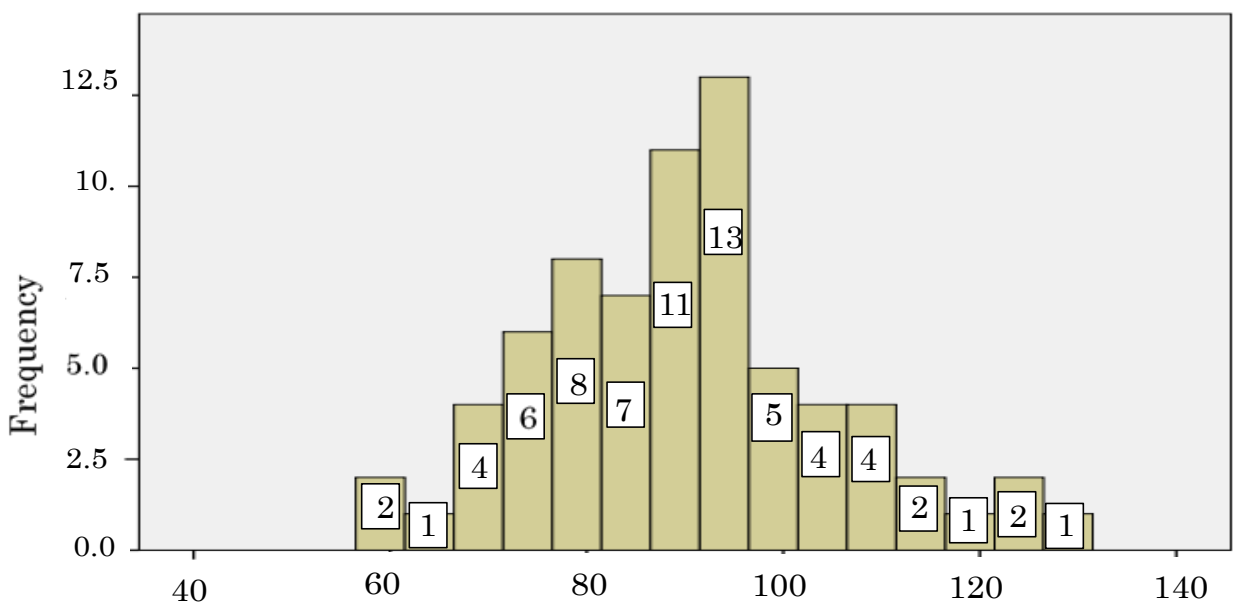

Distribution of intercultural adaptation

Figure 1: Distribution of total score of intercultulal adaptation scale $(\mathrm{N}=71)$

The figure on bar chart indicates the frequency of the total score scaled in vertical axis.

c) Mental health survey

All survey items in GHQ28 were graded with the scoring 0-0-1-1 point system; the lowest score was 0 , the highest score was 17 , and the mean was 2 points (IQR 1.0-5.0). In the present study, 55 (77.5\%) participants scored five or less, and the rest of16 (22.5\%) might develop some mental health problems (See Figure 2 for score distribution). The Cronbach's alpha for GHQ28 in the present study was 0.89, suggesting high internal consistency.

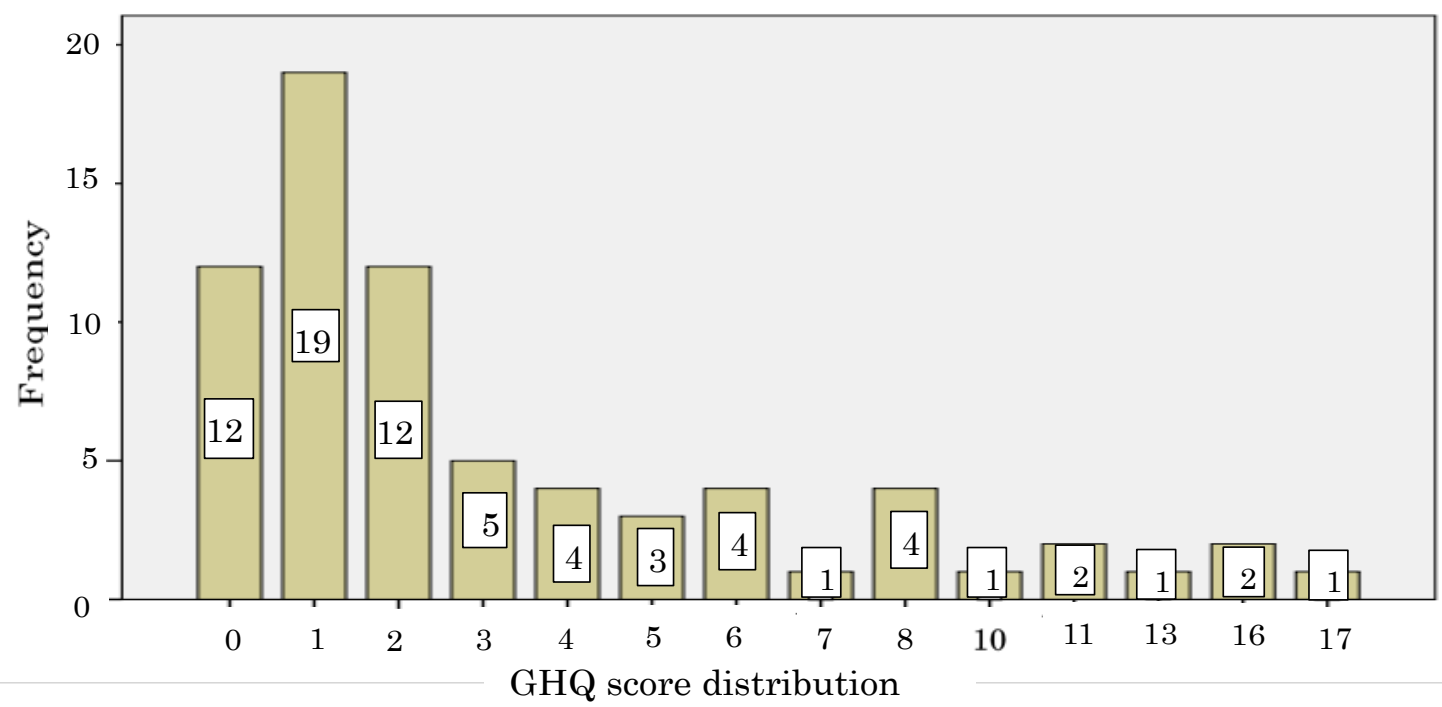

Figure 2: Distribution of $\mathrm{GHQ} 28$ Score $(\mathrm{N}=71)$

The figure on bar chart indicates the frequency of the total score scaled in vertical axis. 
Table 2: Total score of intercultural adaptation scale by area

\begin{tabular}{|c|c|c|c|c|}
\hline Areas & & Average & Mean \pm SD & \% Score \\
\hline \multirow[t]{8}{*}{$\begin{array}{l}\text { Learning/Research } \\
\text { (6 items) }\end{array}$} & & & $16.3 \pm 3.7$ & 54.3 \\
\hline & I don't feel like studying recently & 2.3 & & \\
\hline & $\begin{array}{l}\text { I am not confident in my ability to continue } \\
\text { studying in Japan }\end{array}$ & 2.4 & & \\
\hline & I can't study as I intended & 2.5 & & \\
\hline & I am frustrated because I don't understand & 32 & & \\
\hline & Japanese medical/nursing terminology & 0.4 & & \\
\hline & $\begin{array}{l}\text { I have trouble understanding Japanese even if I } \\
\text { read books and materials in my field }\end{array}$ & 2.8 & & \\
\hline & Recently I have been working very hard to study * & 3.2 & & \\
\hline \multirow[t]{8}{*}{$\begin{array}{l}\text { Mental and Physical } \\
\text { Health/Emotion(7 items) }\end{array}$} & & & $18.2 \pm 5.7$ & 52 \\
\hline & Recently I have been severely exhausted & 3.2 & & \\
\hline & Recently I often feel homesick & 3.4 & & \\
\hline & Recently I have been experiencing anxiety & 2.8 & & \\
\hline & I often become lonely these days & 2.5 & & \\
\hline & Recently I have been unable to sleep well & 2.3 & & \\
\hline & Recently I have been nervous & 2 & & \\
\hline & Recently I have been emotionally unstable & 2.1 & & \\
\hline \multirow[t]{9}{*}{$\begin{array}{l}\text { Interpersonal } \\
\text { Relationships (8 items) }\end{array}$} & & & $16.9 \pm 4.0$ & 56.3 \\
\hline & $\begin{array}{l}\text { I have Japanese friends with whom I can talk } \\
\text { about anything at work * }\end{array}$ & 3 & & \\
\hline & $\begin{array}{l}\text { I have foreign friends (including Indonesians) } \\
\text { with whom I can talk about anything in Japan * }\end{array}$ & 3.4 & & \\
\hline & $\begin{array}{l}\text { I have a Japanese friend with whom I can talk } \\
\text { about anything outside the workplace }\end{array}$ & 2.8 & & \\
\hline & I can't talk casually to my colleagues at work & 2.1 & & \\
\hline & $\begin{array}{l}\text { I don't think I'm ever going to be able to associate } \\
\text { with Japanese people }\end{array}$ & 2 & & \\
\hline & $\begin{array}{l}\text { Recently I have become distressed by my } \\
\text { interpersonal relationships }\end{array}$ & 2.3 & & \\
\hline & I frequently visit my Japanese friend's home * & 2.7 & & \\
\hline & $\begin{array}{l}\text { Overall, I am satisfied with my current } \\
\text { relationships at work * }\end{array}$ & 3 & & \\
\hline
\end{tabular}


Culture (6 items)

Living Comfort/Economy

(7 items)
$16.9 \pm 4.0$

56.3

I have trouble understanding Japanese greetings

and courtesies

I feel that foreign people are conspicuous and

my actions are restricted

As Japanese have strong group consciousness,

I feel it is difficult to participate in their group

I feel frustrated because Japanese expressions

are sometimes indirect

I still don't understand the characteristics of

Japanese society

Before coming to Japan, I didn't get much

information about Japan

$$
18.7 \pm 3.2
$$

The place where I currently live is very

comfortable and satisfying *

The security where I live is very good *

Rent is expensive and life is difficult

I'm very troubled economically

I feel it is difficult to associate with my neighbors.

2.6

The climate here is unbearable

Overall, I am satisfied with my current life in

Japan *

Items marked with * are reversed items. The percentage of each item to the perfect score was calculated as the \% score

\section{d) Mental health and related factors}

Table 3 shows the results, we divided the respondents into two groups based on the results of the mental health survey. Respondents scoring 5 points or less were in the "risk absent group" and those scoring 6 points or more in the "risk present group."All items were analyzed by the Chi-Square test, Fisher's exact test, or an unpaired $t$-test. The results showed a significant difference between the risk absent group and risk present group in four items: "gender," "number of years living in Japan," "status of acquiring the national qualification," and "total score of intercultural adaptation scale." For gender, the percentage of females in the risk present group was significantly higher than the males, and the longer they lived in Japan (more than three years), the more risk the respondents had of having mental problems. The percentage of participants in the risk present group was significantly higher among those who had acquired a national qualification than in those that had not. 
Table 3: Influencing factors for mental health

\begin{tabular}{|c|c|c|c|c|}
\hline & Total $(\mathrm{N}=71)$ & $\begin{array}{l}\text { Risk absent group } \\
\qquad(\mathrm{N}=55)\end{array}$ & $\begin{array}{l}\text { Risk present group } \\
\qquad(\mathrm{N}=16)\end{array}$ & $p$ \\
\hline \multicolumn{5}{|l|}{$<$ Population and household conditions $>$} \\
\hline Gender & & & & $0.02^{\star}$ \\
\hline Female & $57(80.3)$ & $41(71.9)$ & $16(28.1)$ & \\
\hline Male & $14(19.7)$ & $14(100.0)$ & $0(0.0)$ & \\
\hline Age (range : 24-36) & $28.8 \pm 2.7$ & $28.5 \pm 2.7$ & $29.3 \pm 2.8$ & 0.30 \\
\hline Marital Status & & & & 0.05 \\
\hline Single & $49(70.0)$ & $42(85.7)$ & $7(14.3)$ & \\
\hline Married & $21(30.0)$ & 13(61.9) & $8(38.1)$ & \\
\hline Religion & & & & 0.77 \\
\hline Islam & $43(60.6)$ & $34(79.1)$ & $9(20.9)$ & \\
\hline Other & $28(39.4)$ & $21(75.0)$ & $7(25.0)$ & \\
\hline Number of years living in Japan & & & & $0.02^{*}$ \\
\hline Less than 3 year & $35(49.2)$ & $31(88.5)$ & $4(11.4)$ & \\
\hline 3 years of more & $36(50.7)$ & $24(66.7)$ & $12(33.3)$ & \\
\hline Level of Japanese language proficiency & & & & 0.39 \\
\hline Still find daily conversation difficult & $40(56.3)$ & $29(72.5)$ & $11(27.5)$ & \\
\hline No problems in daily conversation & $31(43.7)$ & $26(83.9)$ & $5(16.0)$ & \\
\hline \multicolumn{5}{|l|}{$<$ Socioeconomic conditions $>$} \\
\hline Academic background & & & & 1.00 \\
\hline Vocational school & $58(81.7)$ & $45(77.6)$ & $13(22.4)$ & \\
\hline University or above & $13(18.3)$ & $10(76.9)$ & $3(23.1)$ & \\
\hline Classification of thecurrent workplace & & & & 0.46 \\
\hline Hospital & $50(71.4)$ & $40(80.0)$ & $10(20.0)$ & \\
\hline Aged-care nursing home & $14(20.0)$ & $9(64.3)$ & $5(35.7)$ & \\
\hline Long-term health care facility & $6(8.6)$ & $5(83.3)$ & $1(16.7)$ & \\
\hline \multicolumn{5}{|c|}{ Number of years working at the current workplace } \\
\hline & $2.2 \pm 1.2$ & $2.1 \pm 1.2$ & $2.7 \pm 0.9$ & 0.05 \\
\hline Work pattern & & & & 0.60 \\
\hline Part time & $6(8.7)$ & $4(66.7)$ & $2(33.3)$ & \\
\hline Full time & $63(91.3)$ & $50(79.4)$ & $13(20.6)$ & \\
\hline Target national qualification & & & & 0.50 \\
\hline Nurse & $49(73.1)$ & $40(81.6)$ & $9(18.4)$ & \\
\hline Care worker & $18(26.9)$ & $13(72.2)$ & $5(27.8)$ & \\
\hline Status of acquiring the national qualification & & & & $0.01 *$ \\
\hline Not acquired & $43(61.4)$ & $38(88.4)$ & $4(11.6)$ & \\
\hline Acquired & $27(38.6)$ & $17(63.0)$ & $10(37.0)$ & \\
\hline \multicolumn{5}{|l|}{$<$ Intercultural adaptation scale $>$} \\
\hline Total score & $90.1 \pm 14.9$ & $85.9 \pm 11.8$ & $104.5 \pm 15.7$ & $<0.01^{\star *}$ \\
\hline Learning/Research & $16.3 \pm 4.1$ & $15.4 \pm 3.4$ & $19.1 \pm 3.3$ & $<0.01^{\star *}$ \\
\hline
\end{tabular}




\begin{tabular}{lcccc}
\hline Mental and Physical Health/Emotion & $18.2 \pm 5.7$ & $16.3 \pm 4.1$ & $24.5 \pm 6.0$ & $<0.01^{* *}$ \\
Interpersonal Relationships & $21.2 \pm 4.1$ & $20.5 \pm 3.4$ & $23.13 \pm 3.9$ & $0.01^{*}$ \\
Culture & $16.9 \pm 4.0$ & $16.0 \pm 3.6$ & $19.8 \pm 4.0$ & $<0.01^{* *}$ \\
Living Comfort/Economy & $17.8 \pm 3.2$ & $17.5 \pm 2.918 .2 \pm 3.9$ & 0.46 \\
\hline
\end{tabular}

Values are N (\%) or mean \pm SD (Standard Deviation), ${ }^{*}<0.05,{ }^{*} * 0.01$

For intercultural adaptation, the total score was significantly higher in the risk present group than in the risk absent group. These were significant differences in "Learning/Research," "Mental and Physical Health/ Emotion," "Interpersonal Relationships," "Culture", and "Living Comfort/Economy." In particular, "Mental and Physical Health/Emotion" had the highest score in the risk present group.

\section{Discussion}

\section{a) Intercultural adaptation}

In the subscale of intercultural adaptation, the \%score in the "Culture" area was the highest. The questions items in this area included: "I have a trouble in understanding Japanese greetings and courtesy", "I feel that foreign people are conspicuous and my actions are restricted", "As Japanese have strong group consciousness, I feel it is difficult to participate in their group," and "I feel frustrated because Japanese expressions are sometimes indirect".

As Indonesians are from a country with a culture that uses a more direct way of speaking than Japan, there are many cases where Japanese perceive their wayof speaking as offensive and feel uncomfortable (Obata and Kukihara, 2012). The nursing and care worker candidates have an opportunity to receive a 6month language training course before and after traveling to Japan. However, the Japanese language barrier is large (Endo, 2012). Moreover, Japanese language training after placement at the facility is not consistent, and depending on the facility, EPA candidates may be forced to study by themselves (Endo, 2012). In this study, 40(56.3\%) of the respondents answered that daily conversation was still difficult. In addition to deficiencies in language ability itself, there was a lack of opportunities to learn skills for dealing with Japanese people, such as how to respond in a culturally appropriate way. This condition may lead to maladaptation of Indonesian EPA candidates to Japanese culture. Also, there is some Japanese staff who have difficulty communicating with Indonesian candidates. They feel uncomfortable and confused due to cultural differences (Obata and Kukihara, 2012). These misunderstandings are a major obstacle to mutual understanding.

\section{b) Mental health and related factors}

From the results of this survey, approximately $20 \%$ of the participants were at risk of developing mental problems. The relevant factors were "gender," "number of years living in Japan," "status of acquiring the national qualification," and "total score of intercultural adaptation scale." Regarding "sex," Ozeki et al. (2006) reported that foreign females living in Japan were more mentally stressed and more likely to have mental health problems than foreign males; similar results to the present study, with all participants in the risk group being female. Ozeki et al. (2010) stated that men generally tended to prefer not to show others their emotions if their emotions are regarded as mentally weak, and this may have influenced the mental health results of this study.

Regarding the "a number of years living in Japan," those who stayed in Japan for more than three years had more mental problems than those who stayed for less than three years. According to the EPA framework, the maximum period of stay allowed for obtaining national qualifications is three years for nursing candidates, and four years for care worker candidates (Ministry of Health, Labor and Welfare 2017). If they cannot obtain the national qualification within this period $^{2)}$, they are required to return to their home country after expiration of the period. Therefore when the respondents' stay in Japan exceeds three years, they are in the final year of the period of stay for nursing candidates, and for the care worker candidates, their final chance to pass the national examination is approaching. Under these circumstances, we speculate that mental stress will increase, which will influence on the mental aspect.

The "status of acquiring the national qualification" was also a factor that influenced the mental health of the participants. According to the EPA framework, after obtaining a national qualification, it is possible to work as a regular nurse or a care worker, and there is no restriction to a period of stay (Ministry of Health, Labor and Welfare 2017). When the EPA candidate becomes qualified staff, there may be an influence on their mental health due to the expansion of their roles and responsibilities.

Regarding the "total score of intercultural adaptation scale," in the EPA system, basic Japanese language skills were acquired in the 6-month language training period before and after traveling to Japan; however, there are very few opportunities to experience Japanese culture. As they did not have sufficient means to resolve cultural differences, this resulted in stress (Hatanaka 2018). Ishikawa and Takahashi (1993) also stated that the accumulation of mental and physical fatigue due to living in a different culture for a long time 
affected mental health status. This tendency was seen in the present study as the "total score of intercultural adaptation" was higher in the risk present group than the comparison group.

Furthermore, by the subscales of the intercultural adaptation scale, the score in the "Mental and Physical Health/Emotion" area was highest in the risk present group. Survey items in that area included: "Recently I have been severely exhausted," "Recently I have been unable to sleep well," and "Recently I have been emotionally unstable." If this mental and physical exhaustion continues, it may lead to accidents (Suzuki et al. 2004). Three groups, "Learning/Research," "Interpersonal Relations," and "Culture" also showed high scores. The current support for EPA healthcare workers should be reviewed immediately, especially at facilities that accept female foreign workers.

As indicated by the Japan International Corporation of Welfare Services (JICWELS, 2019), at facilities that accept nursing and care worker candidates train them under certain conditions, with the provision of appropriate training that incorporates information on preparation for national examinations as well as learning support for acquiring specialized knowledge and skills.

Continuous support for Japanese language and culture studies is also a requirement for the recipient facilities, so that the candidates could adapt to the workplace and lifestyle habits (JICWELS 2019). However, as a country, there is no uniform policy regarding the content of these training programs (Nagae et al.2013). Instead, each facility accepting foreign healthcare workers is entrusted to provide the appropriate support. Moreover, since the expense related to the training is the responsibility of the facilities, there is a significant variability in the implementation status among the facilities (Nagae et al.2013, Kim 2010).

In addition to the differences in performance at recipient facilities, our survey found that there is a lack of comprehensive support with a medium- to a long-term perspective that covers cultural adaptation to life in Japan and the work environment, and that looks at life after passing the national examination. The current EPA framework limits the number of national examinations that can be taken and the length of stay, so the biggest priority of the EPA candidates and the recipient facilities are the national examinations (Hatanaka and Tanaka, 2012). In this situation, other support becomes insufficient. Measures such as printing hiragana on top of each Chinese character (Kanji) that expresses a complicated technical term in the national exam, and allowing EPA candidates who fail the exam but achieve a satisfactory total score to be allowed to extend their stay period orre-take the exam are appropriate (Ministry of Health, Labor and Welfare 2019). Even at the national level, there is no mention of how to support continued employment after passing the national examination, because the main focus is succeeding in the national examination (Nagae et al. 2013). This exam-focused support may affect the mental health of foreign healthcare workers and lead to resignation.

It has been eleven years since the first EPA candidates came to Japan; however, little is known to the public regarding the specific support at the facility that accept such foreign healthcare workers. A social welfare corporation reported in Ito (2018) accepted 76 foreign EPA candidates who worked in 11 facilities, of which 30 passed the national exam. The corporation hired its teacher once a week and conducted 4 hours of Japanese language classes paid for by the corporation. The recipient facilities had regular meetings with foreign healthcare workers about their concerns about work and considered together with the foreign healthcare worker what was necessary to enable them to work in Japan for a long time and prevent resignations. Also, corporations that provide a chance for foreign workers to be promoted helps to maintain their motivation. Tukazaki (2010) also reported that at a medical facility, the director stated that support measures to assist foreign nurses pass the national examination were a top priority. After passing the exam, the nurses were given further practical training in all areas of the ward. These approaches were originally developed by the facilities.

Sharing the outcomes of successful cases may facilitate the development of a structured program of support for accepted foreign healthcare workers (Furukawa et al.2012), which is the responsibility of each employing facility in Japan. Also, it may allow for the present support system now centered on measures for passing the national exam, to transform into one that provide mid- and long-term support even after candidates have passed the examination.

Finally, Japan is facing an unprecedented aging society problem, and medical care needs are expected to increase in the near future. To provide enough services with the proper quality, it is essential to secure human resources in the field of medical and nursing care. It is vital to create an attractive working environment and effective support, so that foreign workers can work in Japan for as long as possible.

\section{Supplementary note}

1. In this study, "healthcare workers" referred to nursing and care worker candidates, and those who passed the national examination.

2. During the period of stay, nursing candidates had the opportunity to take the national examination three times in three years, whereas care worker candidates have the opportunity to take the national exam once in the fourth year.

\section{References Références Referencias}

1. Baker, W. R., McNeil, O. V., Siryk, B. 1985, Expectation and reality in freshman adjustment to college, Journal of Counseling Psychology 32: 94-103. 
2. Baker, W. R., Siryk, B. 1986, Exploratory intervention with a scale measuring adjustment to college, Journal of Counseling Psychology 33: 31-38.

3. Endo, O. 2012, The difficulty of vocabulary for onsite care workers: Language problems among foreign care workers, Research journal of care and welfare 19(1), 94-100.

4. Fukunishi I. 1990, The assessment of cut of point of the General Health Questionnaire (GHQ) in Japanese version. Clinal Psychology 3: 228-234.

5. Goldberg, D. P., Hillier, V. F. 1979, A scaled version of the General Health Questionnaire. Psychological Medicine 9: 139-145.

6. Hatanaka, K., Tanaka, K. 2012, The research note about the background of the cultural adaptation problems of foreign nurses and care worker candidates in Japan: From the view of EPA systems and its circumstances, Bulletin of Graduate School of Social and Cultural Sciences, Okayama University 34: 79-90.

7. Hatanaka, K., Yamamoto, E., Tanaka, T. 2018Intercultural Stress of Foreign Care Workers in Japan: Role of Intercultural Intermediator, The Japanese journal of stress sciences: 33(1), 45-56.

8. Ikeda Keita. 2014, $20 \%$ of foreign nurses and care workers return home, June 24, Yomiuri Shimbun.

9. Ishikawa, T., Takahashi, S. 1993, Cultural Stress and Psychosomatic Disease, Human Mind 49: 75-79.

10. Japan International Corporation of Welfare Services. 2019, Pamphlet on acceptance of foreign nurses and care workers based on the 2020 EPA. [Reference date: 26 November 2019]. Available from URL: https://jicwels.or.jp/?page id=16

11. Kaneko, A., Tsutsui, T., Uchiyama, $\bar{M}$. 2004, Mental health status, shift work, and occupational accidents among hospital nurses in Japan, The Journal of Occupational Health 46: 448-454.

12. Kim, M, 2010, The training for care worker candidate who come from Indonesia to Japan due to EPA and their perception of the national qualification of care worker. Otsuma Women's University Bulletin of Faculty of Human Relations12: 37-44.

13. Ministry of Health, Labor and Welfare, 2017, Acceptance of candidates for nurses and care workers based on the 2017 Japan-Indonesia Economic Partnership Agreement, [reference date: September 19, 2018] Available from URL : https: //www.mhlw.go.jp/file/06-Seisakujouhou-11650000Shokugyouanteikyokuhakenyukiroudoutaisakubu/ indonesia syosai H29.pdf.

14. Ministry of Health, Labor and Welfare, 2018, Acceptance of foreign nurse/care worker candidates from Indonesia, Philippines and Vietnam, [reference date: August 24, 2018] Available from URL: https: //www.mhlw.go.jp/stf/seisakunitsuite/bunya/koyou_r oudou /koyou /gaikokujin/other22 /index.html.
15. Ministry of Health, Labor and Welfare, 2019, Extension of stay of period of Indonesian, Filipino and Vietnamese nurse and care worker candidates under the Economic Partnership Agreement (EPA) [reference date: August 24, 2018] Available from URL: https://www.mhlw.go.jp/content/11650000/00 0484757.pdf

16. Nagae $M$, Iwase $T$, Furuzawa $A$, Tsyubonouchi $C$, Shimai S, Ando T. 2013, Study on the adaptation of EPA-based Indonesian nurse candidates to their workplace environment in Japan. Japanese Red Cross Toyota College of Nursing Bulletin8: 197-119.

17. Nakagawa Y, Daibow I. 1985, Japanese version of the GHQ mental health questionnaire guide. Tokyo: Nihon Bunka Kagakusha.

18. Obata, J., Kukihara, H. 2012, Qualitative Analysis of Cross-cultural Conflict in the Frontlines of Health Care: Through the Cultural Contact Indonesian Applicants for Nurse, nursing care research 11(2): 59-68, 2012.

19. Onishi, M., 2003, Mental Health of Foreign Residents in Japan, Education and Medicine 51: 79-84.

20. Ozeki, N., Knowles, A., Ushijima, H., Asada, Y. 2006. Analysis of transcultural stress factors and the mental well-being of foreign Chinese-speaking students in Aomori, Aomori University of Health and Welfare 7: 9-16.

21. Ozeki, N., Knowles, A, Asada, Y. 2010, Analysis of Intercultural Stress and Adaptation of Foreign Students in Japan, Journal of Japan Academy of Human Care Science 3 (1): 25-39.

22. Sasaki, H., Mizuno, H. 2000, A longitudinal study of cross-cultural adjustment process for foreign Japanese language teachers in Japan, Bulletin of International Center for Japanese Language 10: 1-16.

23. Suzuki, K., Ohida, T., Kaneita, Y., Yokoyama, E., Miyake, T., Harano, S., Yagi, Y., Ibuka, E., Uehara, A. 1990, Basic research on advancement of Japanese language and adaptation of foreign students, Grant-in-Aid for Scientific Research Grants.

24. Tukazaki, A. 2010, What is the training method for foreign nurses and the merits? Nursing Business 4 : 48-52. 